\title{
A família revelando-se como um ser de direitos durante a internação hospitalar da criança
}

The family revealing itself as a being of rights during hospitalization of the child

La familia revelando-se como un ser de derechos durante la hospitalización del niño

\author{
Daiani Modernel Xavier', Giovana Calcagno Gomes', \\ Edison Luiz Devos Barlem', Alacoque Lorenzini Erdmann" \\ ' Universidade Federal do Rio Grande, Escola de Enfermagem, Programa de Pós-Graduação em Enfermagem. \\ Rio Grande - RS, Brasil. \\ "Universidade Federal de Santa Catarina, Centro de Ciências da Saúde, Departamento de Enfermagem, \\ Programa de Pós-Graduação em Enfermagem. Florianópolis-SC, Brasil.
}

Submissão: 19-08-2012 Aprovação: 06-11-2013

\begin{abstract}
RESUMO
Estudo descritivo, de abordagem qualitativa, realizado no segundo semestre de 2011, em uma Unidade de Pediatria de uma cidade do extremo sul do país. Objetivou-se conhecer as situações em que as famílias se revelam como seres de direito durante a internação hospitalar da criança. Participaram quinze familiares cuidadores divididos em três grupos amostrais. A coleta de dados foi realizada por meio de entrevistas semiestruturadas, e os dados foram analisados pela análise aberta, axial e seletiva. Teve como referencial metodológico a Teoria Fundamentada nos Dados. Verificou-se que a família revela-se como um ser de direitos, quando a reconhecem como tal; solicita e luta por seus direitos; sugere melhorias para o cuidado e mantém sua autonomia, mesmo que tenha que se submeter às decisões da equipe em prol da criança. Concluiu-se ser fundamental permitir que estas sejam famílias no hospital, possibilitando o exercício de seus direitos e cidadania.

Descritores: Família; Criança; Direito à Saúde; Síndrome de Imunodeficiência Adquirida; Enfermagem.
\end{abstract}

\begin{abstract}
This is a descriptive study with a qualitative approach, carried out during the second half of 2011, in a Pediatric Unit in a city in the extreme South of Brazil. The study aimed to understand the situations in which families reveal themselves as beings of rights during the hospitalization of the child. Fifteen family caregivers participated, divided into three sample groups. Data collection was conducted through semi-structured interviews, and the data were analyzed using open, axial and selective analysis. The study had the Grounded Theory as methodological framework. It was found that the family revealed itself as a being of rights, when recognized as such, is called and fights for their rights; suggests improvements for the care and maintains its autonomy, even if it has to submit to the decisions of the team in the child favor. It was concluded that is essential to allow them to be families in the hospital, enabling the exercise of their rights and citizenship.
\end{abstract}

Key words: Family; Child; Health Rights; Acquired Immunodeficiency Syndrome; Nursing.

\section{RESUMEN}

Estudio descriptivo con abordaje cualitativo, realizado durante el segundo semestre de 2011, en una Unidad Pediátrica de una ciudad del sur del país. El estudio tuvo como objetivo comprender las situaciones en que las familias se revelan como seres de derechos durante la hospitalización del niño. Participaron quince cuidadores familiares, divididos en tres grupos. La recolección de datos se realizó a través de entrevistas semi-estructuradas, y los datos fueron analizados utilizando el análisis abierto, axial y selectivo. Tuvo como referencial metodológico la Grounded Theory. Se observó que la familia se revela como un ser de derechos, cuando son reconocidas como tales, llamadas y luchar por sus derechos; sugiere mejoras en la atención y mantiene su autonomía, incluso si tiene que someterse a las decisiones del equipo a favor el niño. Se concluyó que es esencial permitir que sean familias en el hospital, lo que permite el ejercicio de sus derechos y ciudadanía.

Palabras clave: Familia; Niño; Derechos de Salud; Síndrome de Inmunodeficiencia Adquirida; Enfermería. 


\section{INTRODUÇÃO}

Na internação hospitalar da criança, geralmente, ela se faz acompanhar por um dos membros de sua família. É no familiar que ela busca apoio e proteção, pois o seu cuidado contempla o componente afetivo, tão necessário neste momento. Verifica-se que o cuidado à criança não é exclusividade da Enfermagem ou dos outros profissionais da saúde no hospital. A família também cuida, só que baseada nos seus referenciais $^{(1)}$. Assim, o cuidado à criança passa a ser compartilhado entre a equipe de enfermagem e o familiar cuidador que a acompanha.

Ao ser envolvida no cuidado, a família tem o direito de conhecer o projeto terapêutico proposto para seu filho e de ser instrumentalizada acerca do processo de hospitalização, para que tenha condições de enfrentá-lo. A experiência da internação no hospital, em razão das suas características e rotinas, muitas vezes rígidas e inflexíveis, pode gerar desconforto no paciente, impessoalidade, dependência da tecnologia, isolamento social, falta de privacidade, perda de identidade e da autonomia, dentre outros, rompendo bruscamente com seu modo de viver, incluindo suas relações e papéis. Neste caso, a identidade e a autonomia podem ser afetadas, comprometendo sua capacidade de escolher, decidir, opinar e expressar-se ${ }^{(1)}$.

A hospitalização para a criança pode ocasionar um sentimento de ameaça, agressão, medo do desconhecido, pois é nesse momento que ocorre a separação de todos os objetos significativos de sua segurança. Por outro lado, à família pode apresentar angústia, ansiedade e sentimento de culpa. Informar a criança e sua família sobre os seus direitos durante a hospitalização garante uma maior compreensão da situação e pode aliviar parte dos sentimentos negativos que eles possam sentir ${ }^{(2)}$.

Verifica-se que, em muitas situações, a família revela-se como um ser de direitos no hospital. Ela o faz quando se reconhece como tal; solicita seus direitos e luta para manter sua autonomia. Apesar disso, ainda, há situações em que se submete à equipe de saúde pelo bem da criança $^{(3-4)}$.

Quando se reconhecem como um ser de direitos, as famílias manifestam seus pensamentos e, é através destas manifestações, que a equipe de saúde pode avaliar seu prestígio e imagem, frente a elas. Em diversas situações lutam pelos seus direitos e, a partir de suas vivências e dos significados que atribuem às suas experiências sugerem melhorias, com vistas a facilitar os cuidados à criança no hospital.

A família utiliza como estratégias o reclamar, o questionar, o negar-se, o brigar, o insistir, o bater o pé e o exigir, exercitando, assim, seu poder e sua resistência frente à equipe de saúde. Ao entrar no hospital, sofre e, fragilizada, em muitas situações, passa a depender da ajuda dos profissionais para tomar decisões acerca do processo saúde e doença da criança. Assim, luta pelo seu direito através da ação dos profissionais por reconhecê-los como seus representantes, capazes de auxiliá-los neste momento(5).

A família, através da sua participação ativa no cuidado à criança, procura manter sua autonomia frente à equipe de saúde. Neste sentido, compartilha decisões sobre o cuidado da criança e tenta participar, conversando acerca do plano terapêutico, a fim de subsidiar suas decisões, negociando com a equipe o cuidado, tomando decisões a partir das avaliações que realiza(6).

Aquelas famílias cujo familiar cuidador da criança não possui uma boa rede de suporte social na sua comunidade expressam que, mesmo no hospital, não podem perder o controle da situação no domicílio. Precisam continuar mantendo sua autonomia, também, em casa, como forma de dar conta das necessidades dos outros filhos que lá se encontram, mesmo sentindo-se sobrecarregadas.

Em nosso país, a doença é um negócio altamente lucrativo e o Sistema Único de Saúde vigente ainda não conseguiu garantir o acesso aos serviços de saúde de forma igualitária para todos ${ }^{(3)}$. Atualmente, ao entrar no mundo do hospital verifica-se que a família exerce seu direito a um atendimento de qualidade quando luta para manter sua autonomia, quando negocia e compartilha o cuidado da criança com os membros da equipe de saúde, quando mobiliza uma rede de apoio social para auxiliá-la a cuidar da criança.

Ao reconhecer-se como um ser de direitos, passa a reivindicá-los, mesmo que no hospital o poder penda mais para o lado dos profissionais. Ainda, quando, aparentemente, se submete às vontades da equipe, é porque, até certo ponto, as entende como necessárias para o benefício da criança. Desta forma, a aparente submissão revela-se como uma forma de cuidado familiar à criança ${ }^{(7)}$.

Participar do cuidado à criança no hospital, durante sua internação, possibilita às famílias não somente desenvolverem suas habilidades técnicas. Através da sua participação no cuidado, as famílias estão conhecendo mais o cotidiano do hospital e, a partir deste conhecimento, estão desenvolvendo sua consciência crítica e sua autonomia, fortalecendo seu poder de reivindicação, tornando-se mais participativas no processo de tomada de decisões, quanto ao cuidado à criança e aptas a fazerem sugestões para sua melhoria ${ }^{(8)}$.

Nesse contexto, este estudo teve como objetivo conhecer as situações em que as famílias se revelam como seres de direito no hospital durante a internação da criança.

\section{METODOLOGIA}

Trata-se de uma pesquisa descritiva de abordagem qualitativa. É qualitativa porque se refere à pesquisa sobre a vivência das pessoas, experiências vividas, comportamentos, emoções e sentimentos, e também sobre o funcionamento organizacional, movimentos sociais, fenômenos culturais e interação entre nações. Refere-se à pesquisa descritiva porque descreve o fenômeno investigado, possibilitando conhecer os problemas vivenciados ${ }^{(9)}$.

Foi realizada no segundo semestre de 2011 e teve como referencial metodológico a Teoria Fundamentada nos Dados (TFD), que consiste na coleta, codificação e comparação simultânea e sistemática dos dados, possibilitando explorar o fenômeno investigado gerando teoria que explique e possibilite a compreensão de fenômenos sociais e culturais ${ }^{(10)}$. 
O estudo foi desenvolvido na Unidade de Pediatria de um Hospital Universitário (HU), no sul do Brasil, que tem como campo de atuação o ensino, a pesquisa, a extensão e a assistência à saúde. Participaram do estudo dezoito familiares cuidadores de crianças internadas no setor, no período de realização do estudo, sendo que quinze foram distribuídos em três grupos amostrais, conforme orienta a TFD e três participaram da validação dos dados.

Como critério para a escolha dos participantes utilizou-se ser cuidador significativo da criança e prestar-Ihe cuidados diretos no hospital durante a realização da coleta dos dados. Todos assinaram o Termo de Consentimento Livre e Esclarecido em duas vias, ficando uma cópia com cada participante. Foram identificados pela letra $\mathrm{F}$ seguida do número da entrevista, como forma de garantir seu anonimato.

A coleta de dados foi realizada através de entrevistas semiestruturadas, operacionalizadas através de um plano de entrevista, com cada cuidadora. Foram questionados acerca das situações em que se revelam como seres de direito no hospital. Estas foram agendadas com cada familiar, gravadas e transcritas para análise.

O processo de análise inicial deu-se através da Codificação aberta dos dados, em que as falas foram minuciosamente detalhadas, através do exame do conteúdo, linha por linha, de forma a elaborar as unidades de análise. Na Codificação axial foram relacionadas categorias às suas subcategorias, ao longo das linhas de suas propriedades e dimensões. E na Codificação seletiva, gerou-se o modelo paradigmático. Ele estabelece uma relação entre as categorias, envolvendo, respectivamente, causa, fenômeno, contexto, condições intervenientes, estratégias de ação/interação e consequências ${ }^{(9)}$.

Foram respeitados os princípios éticos da pesquisa envolvendo seres humanos, conforme a Resolução 196/96 $6^{(11)}$. O projeto do estudo foi submetido ao Comitê de Ética da Universidade Federal do Rio Grande/ FURG recebendo parecer favorável sob número 133/ 2011.

\section{RESULTADOS}

A análise dos dados mostrou que a família revela-se como um ser de direitos, quando a reconhecem como tal; solicita e luta pelos mesmos; sugere melhorias para o cuidado à criança; mantém sua autonomia no hospital; tendo que submeter-se às decisões da equipe. Apesar disso, ainda, há situações em que a família submete-se à equipe de saúde pelo bem da criança.

\section{Sendo reconhecida como um ser de direitos}

As famílias das crianças internadas sabem que têm direitos de estar no hospital e de serem bem atendidas pelos profissionais que lhes assistem.

Até agora estão sendo atendidos meus direitos aqui no hospital, se não estivessem eu reclamaria, pois são os meus filhos. Para mim é tranquilo, eu não tenho nada para reclamar (F2).

Acho que meus direitos estão sendo respeitados aqui no hospital. Tudo o que pedi para a equipe, até agora, foi feito sem cara feia, sendo bem prestativos comigo. Entram no quarto já brincando (F3).

Reconhecem-se como seres de direitos quando são informadas acerca do processo terapêutico instituído para a criança e acerca das normas e rotinas do hospital.

Quando foi hoje a enfermeira veio informar que pode ser feita uma por turno, pois o médico deixou prescrito. Sinto-me bem atendida, ainda mais quando vem uma enfermeira informando que em caso de alguma necessidade é só comunicar (F1).

Acreditam ter seus direitos atendidos frente à solicitude $\mathrm{e}$ presença constante dos profissionais da equipe.

Aí vem a moça da copa: 'o que a senhora precisar pode me chamar'. Vem novamente, o pessoal da enfermagem, perguntando: 'se precisar de alguma medicação prescrita é só nos falar' (F1).

Acho que os direitos que tenho estão sendo cumpridos, pois as medicações estão vindo na hora certa, bem como estamos sendo atendidos quando solicitamos atendimento à equipe (F5).

Ao se reconhecerem como seres de direito as famílias manifestam seus pensamentos e, é através destas manifestações, que a equipe de saúde pode avaliar seu prestígio e imagem, frente às famílias.

A partir do momento que meu filho é bem tratado e que não falham com ele, pois ele precisa ser tratado. Aí, é que percebo não só o meu direito de mãe sendo atendido. Das outras vezes que meu filho internou no hospital, em função de crises convulsivas que ele tem de duas a três vezes, no ano também fui bem atendida. É um direito nosso. Durante todos os momentos da internação do meu filho, não fui tratada com indiferença, foi sempre tudo bem (F4).

\section{É uma equipe bem preparada e humana (F5).}

\section{Não sendo reconhecida como um ser de direitos}

As famílias de crianças internadas no hospital vivenciam situações em que percebem ter tido seus direitos negligenciados.

Foi bastante difícil, pois quando cheguei ao hospital, por volta do meio-dia, custaram para internar meus gêmeos que só foram ser internados às quatro e meia da tarde. Os dois passando mal e, mesmo assim, eu custei para conseguir sequer consultar com um pediatra, se não passam eles na frente dos outros que estavam na fila eu acho que eu iria surtar. Achei uma falta de respeito (F2).

Na entrada do hospital, eu tive que dizer uma mentirinha para eles me deixarem entrar fora do horário da visita. Assim, eu me sinto lesada, quanto a esse meu direito, visto que sou eu quem cuidou da minha neta (F5). 


\section{Lutando pelos seus direitos}

As famílias são ativas no exercício de sua cidadania no hospital. Sua permanência nesse contexto parece estar imprimindo outra dinâmica ao processo de trabalho, pois esta interação com o ambiente e com os profissionais da equipe de saúde faz com que conheçam o cotidiano hospitalar, reivindicando uma maior participação no processo de cuidado, solicitando cuidados para a criança e para si e avaliando o cuidado prestado pela equipe.

Se eu achar necessário eu peço algum exame. Estou sempre conversando com o médico. Às vezes, eu até discuto com ele, porque eu sou insistente demais (F11).

Quando eu acho que poderiam estar fazendo mais por ela e não estão, eu solicito. Se uma medicação foi suspensa, como aconteceu, e os sintomas voltaram, já peço para o médico o retorno da prescrição deste remédio. É aquela coisa do acompanhamento de mãe. Faço isso o dia inteiro: - Óh, faltou o soro, molhou o lençolzinho, enfim, este tipo de coisas. Conversando, discutindo, pedindo. Eu vou pedir, vou brigar, vou discutir, mas eu quero aquilo ali que é um direito dela, porque eu sou uma cidadã e eu tenho direito. É batendo o pé e exigindo (F12).

Na luta por seus direitos evidenciou-se que, muitas vezes, as famílias se submetem aos cuidados da equipe por confiar na mesma e acreditar que esta, por ter maior conhecimento, acerca do processo de adoecimento e necessidades de cuidados das crianças, possuem condições de decidir o que é melhor para a criança.

Na verdade, só em estar aqui a gente já está exercendo do direito à internação da criança. Mas, no mais, tem muitas coisas que a gente desconhece, não sabe dizer o que é meIhor para a gente. Então, a gente se entrega nas mãos dos nossos médicos, enfermeiras. Porque eles é quem sabem mais e a gente confia neles (F13).

Deixo por conta deles, porque eles sabem o que fazer. $O$ que vai ser melhor ou não. Se eu interferi foi pra pedir que não viesse cenoura porque ele não come e pedi que aumentasse o leite, porque ele estava chorando com fome, mas no mais eu não me meto em nada, nem em medicação, nem nos procedimentos, se tem que furar, colocar um soro, fura. Paciência! Pra isso, eu já assinei lá embaixo para deixar fazer o que fosse necessário. Eu confio muito neles, pois já internei mais de uma vez (F14).

\section{Sugerindo melhorias para o cuidado à criança no hospital}

Quando é dada oportunidade para as famílias, as mesmas, a partir da sua experiência com a hospitalização, têm condições de fazer sugestões para a melhoria das condições em que o cuidado à criança é prestado na Pediatria.

Se me perguntarem eu sei dizer o que poderia ser feito para melhorar o cuidado aqui. A gente passa algum tempo internada e passa a conhecer a Unidade, as rotinas. Já estive aqui outras vezes (F6).

Tem coisas aqui que poderiam ser diferentes e não alteraria muito a rotina. la melhorar pra gente: a comida vir aqui em cima, poder trocar o acompanhante em diferentes horários (F10).

Outras sugestões relacionaram-se à possibilidade de mudanças em normas e rotinas da instituição como a flexibilização dos horários de visita, a permissão para a entrada de alimentos na unidade, a possibilidade de se lavar e estender suas roupas no hospital.

Acho que deveria poder entrar as visitas fora de horário, porque às vezes não se pode vir quando a gente quer e a gente precisa que nos tragam o que a gente precisa. Não iria atrapalhar (F15).

Poderia ser diferente no caso de liberar a comida para entrar. Eu acho que seria justo. É claro que as enfermeiras não têm culpa, mas elas sabem que a gente fica com fome. A última refeição é às $20 \mathrm{~h}$ da noite. $E$ se a criança chora a noite toda, tu tens que ficar acordada. Tu rói o quê? Tem o que roer? Acho que poderia entrar comida (F12).

O hospital nos dá muito, mas tinham que facilitar este lado aí. Teria que ter no hospital um local que a gente pudesse lavar e secar a nossa roupa (F10).

Também sugeriram a possibilidade de melhoria das condições, nas quais as famílias são instaladas possibilitando-lhes conforto para cuidar. Desta forma, as famílias nos mostraram novas possibilidades de cuidado a serem resgatadas e construídas, durante nosso processo de cuidar.

Eu acho que seria importante ter mais conforto aqui para que nós, mães, ficássemos melhor. Ter uma cadeira meIhor, até uma cama pra gente (F15).

Ver a temperatura da criança toda hora. Se a criança está bem eu acho que não tinha necessidade. Atrapalha, não deixa a gente dormir. E não é só isso, sempre tem uma coisa para fazer. Eu acho que isso não precisava (F11).

\section{Mantendo sua autonomia no hospital}

A família, através da sua participação ativa no cuidado à criança, procura manter sua autonomia frente a esta e à equipe de saúde. Neste sentido, a família participa das decisões, quanto ao cuidado da criança e tenta se impor, conversando acerca do cuidado, a fim de subsidiar suas decisões, negociando com a equipe o cuidado, tomando decisões a partir das avaliações que realiza.

Eu mantenho a minha autonomia, eu não complico, só vejo se tudo está direitinho, se os remédios estão direitinho. 
Porque a gente cuida junto e um ajuda o outro (F10).

Aqui é assim, todo mundo cuida. Cada um faz a sua parte. A gente negocia, combina tudo pelo melhor para a criança (F9).

Aquelas famílias cujo familiar cuidador da criança no hospital não possui uma boa rede de suporte social na sua comunidade expressaram que, mesmo no hospital, não podem perder o controle da situação no domicílio. Precisam continuar mantendo sua autonomia, também, em casa, como forma de dar conta das necessidades dos outros filhos que lá se encontram. Precisam continuar tomando todas as decisões em relação ao cuidado das outras crianças em casa, mesmo sentindo-se sobrecarregadas.

Eu não tenho ninguém para tomar conta das coisas na minha casa. Então, eu estou aqui, mas, também, estou em casa. Vou e determino as coisas para os outros filhos. A comida, os temas, tudo. Vejo se o marido está cuidando das roupas, dos uniformes, das contas, das compras. Não é fácil (F14).

\section{Tendo que se submeter às decisões da equipe}

Mostrou que a família, como se encontra em um mundo desconhecido, no qual exerce menos poder, em muitas situações, termina se submetendo às decisões da equipe de saúde. Nas relações da equipe com as famílias, parece haver uma assimetria de poder e, invariavelmente, a equipe procura impor às famílias suas opiniões, exercendo sobre elas certa dominação. Por sua vez, as famílias possuem capacidades diferentes de negociação e de controle sobre suas próprias vidas. Este fato associado à vulnerabilidade em que se encontram no hospital facilita a submissão das famílias à equipe.

Eu acato tudo que o médico e as enfermeiras dizem. Eles sabem mais Ele quer dar alta com a guria ruim, mas a gente vai dar alta sabendo que daí a um tempo vai ter que voltar de novo com a criança (F8).

Olha tem muita coisa que acontece que a gente termina tendo que aceitar, nem que não concorde muito, porque a gente pensa na criança, no bem dela. A gente não quer criar confusão, quer um clima bom... Então, aceita (F11).

Os profissionais, como têm maior controle sobre o território do hospital e sobre as informações acerca do diagnóstico e tratamento da criança, têm mais condições de impor-se às famílias. No entanto, esta aparente submissão pode não significar uma apatia da família, mas, sim, uma estratégia de enfrentamento possível da situação, em benefício da criança.

A gente é de pouca informação acerca da doença, vê nossa filha doente, bem ruinzinha, então, o que eu não sei eu acato. A gente precisa confiar neles. Então, por isso a gente acata tudo. Teríamos que entender mais para dizer que não (F12).

\section{DISCUSSÃO}

Ao cuidar a criança no hospital a família revela-se como um ser de direitos. Em nosso país, apesar da saúde ser um direito de todos e um dever do Estado ainda vê-se que o Sistema Único de Saúde vigente ainda não garante acesso aos serviços para todos. Tal fato, talvez ocorra porque muitos desconhecem seus direitos e a forma de reivindicá-los, apesar de esta realidade estar, aos poucos, mudando ${ }^{(3)}$.

A família tem ocupado lugar diferenciado, na organização do trabalho em enfermagem, à medida que conquistou direito à sua permanência no hospital e à participação no cuidado à criança, adquirindo maior autonomia no setor, mudando a forma como o processo de trabalho desenvolvido é organizado, dando-Ihes maior autonomia. Neste sentido, o atendimento na Pediatria passa a voltar-se para além das intervenções clínicas da criança, para a integralidade do seu cuidado ${ }^{(8)}$.

Torna-se necessário a inclusão de estratégias que busquem viabilizar arranjos diferenciados para os serviços de saúde, voltados para a integralidade do cuidado, e que oportunize maior autonomia aos sujeitos. Assim, é necessário reorganizar o cuidado hospitalar para que atenda integralmente às necessidades singulares de cada família que convive com esta realidade ${ }^{(12)}$.

A participação ativa da família no cuidado fortalece os vínculos com a equipe de saúde que passa a valorizar sua cultu$\mathrm{ra}$, valores e crenças, quando institui o plano de cuidados $^{(7)}$. Ao adentrar o ambiente do hospital, tendo este direito garantido, ocorre a formalização do cuidado familiar. Neste sentido, viabilizando sua particularidade e autenticidade, em prol da melhora do estado de saúde da criança ${ }^{(13)}$.

A família revela-se como um ser de direitos quando é garantida sua participação no sistema de saúde ${ }^{(3)}$. No hospital, a família favorece a troca de informações, auxilia a tornar os procedimentos mais aceitáveis à criança, favorece a prevenção de acidentes e a terapêutica instituída, propiciando que esta receba um atendimento humanizado e acolhedor. Além disso, a família garante que a criança receba informações acerca do seu estado de saúde, de acordo com o seu entendimento $^{(14)}$.

Porém, frente à política das instituições de saúde, o comportamento impositivo dos profissionais de saúde reproduz relações de poder em relação ao cuidado, tornando pouco reconhecido o direito das famílias ao compartilhamento das decisões e do plano de cuidados da criança ${ }^{(8,15)}$. A inserção de um acompanhante e o seu envolvimento com o processo terapêutico não se trata de uma simples questão, implicando em reorganização do trabalho e compreensão da dinâmica das relações interpessoais entre os agentes envolvidos no cuidar ${ }^{(13)}$.

Propiciar que a família exerça seu direito à permanência no hospital implica em negociar com ela o cuidado à criança, respeitando suas crenças e valores e aproximando o cuidado profissional ao cuidado popular. A família promove um cuidado que é deliberado pela equipe de enfermagem, aliviando, de certa forma, o trabalho que por essa deveria ser realizado ${ }^{(13)}$.

Reconhece-se, no entanto, que a hospitalização traz dificuldades para o cotidiano da família, que poderá compartilhar momentos difíceis. Diante das dificuldades, frente à 
internação hospitalar da criança, a família passa a lutar pelos seus direitos, no intuito de exercer sua cidadania(7). Com esse pressuposto, passam para a equipe o que precisam na unidade, pedem informações, reclamam do atendimento e conferem o horário das medicações, no intuito de compartilharem o cuidado com a equipe.

Além disso, passam a sugerir melhoras no cuidado à criança no hospital(8). Para tanto, a liberação da comida para o familiar cuidador, mais carga horária para visitas e melhores condições de instalação, remetem às reivindicações, fazendo-os se sentir participativos e autônomos no cuidado hospitalar.

Todavia, no ambiente hospitalar, as famílias ainda se deparam com o poder exercido pela equipe de saúde, tendo que se submeter às decisões da mesma, em prol da melhora da criança ${ }^{(3-4)}$. Com isso, ficam apreensivas ao chegar ao hospital, enfrentando a necessidade de internação por não poderem ir embora sem o tratamento hospitalar.

Assim, torna-se necessário repensar as práticas do cuidado à criança hospitalizada, construindo uma relação dialógica como primeiro passo para a construção do vínculo entre profissionais de saúde e família. Para garantir o cuidar integral, deve-se considerar a necessidade de estabelecer vínculos, confiança e responsabilização entre família e profissionais da equipe. Um olhar e um agir ampliados para a família, tornando-a parte do processo, no âmbito da assistência à criança hospitalizada, garante que a mesma tenha seus direitos garantidos e possibilita que a mesma revele-se como um ser de direitos.

\section{CONCLUSÕES}

O estudo possibilitou conhecer as situações em que as famílias se revelam como seres de direito e convivem com as normas e rotinas no hospital. A partir dos dados evidenciou-se que a família revela-se como um ser de direitos à medida que é garantida sua participação no sistema de saúde, sentindo-se acolhidas pelos profissionais da equipe. Todavia, quando a mesma não compartilha as decisões e o plano de cuidados, os familiares sentem seus direitos negligenciados.

Dessa forma, a família passa a lutar pelos seus direitos, objetivando sua autonomia, bem como o compartilhamento das decisões com a equipe de saúde, sugerindo melhorias para o cuidado, para não terem que se submeter às decisões da mesma.

Torna-se importante abordar a família de forma respeitosa, garantindo-lhe a manutenção do sigilo, favorecendo a construção de vínculos e o estabelecimento de confiança, atendendo-a nas suas necessidades específicas. Acredita-se que a família subsidiada poderá tornar-se protagonista da sua vida, sentindo-se apoiada e assessorada nas suas decisões.

É fundamental que os profissionais da equipe de saúde, atuantes em Unidades de Pediatria, criem e aprimorem o cuidado às crianças e a seus familiares cuidadores. Esse momento deve fazer parte do planejamento dos cuidados oferecidos, levando em conta o contexto social no qual estão inseridos. Com isso, a família poderá se sentir instrumentalizada para o cuidado à criança, bem como valorizada e respeitada pela equipe de saúde, tendo seus direitos respeitados.

Como a família encontra-se fragilizada, pela internação hospitalar de seus filhos, esta, na maioria das vezes, fica a mercê das decisões dos profissionais. Assim, compete ao enfermeiro tomar a iniciativa de integrá-la ao processo de cuidado da criança, na busca por relações menos conflitantes e mais efetivas, no sentido de se propiciar um cuidado mais qualificado, sensível e humano.

Para que isto ocorra, é necessária uma Enfermagem atuante, que priorize o aspecto educativo da assistência, e que, tanto a família, como a equipe de enfermagem, interaja e se comunique de forma satisfatória. Esta participação deve ser discutida entre família e enfermagem, planejada conjuntamente, de acordo com o preparo, desejo e disponibilidade entre ambas. Planejamento estratégico do cuidado, de que a enfermagem e as famílias dispõem para auxiliar as crianças neste momento.

Conclui-se que o enfermeiro precisa compreender a família como um grupo que constrói a sua história, que atribui significados às experiências vividas e, a partir desses, age. Frente à necessidade da internação hospitalar da criança a família enfrenta conflitos e contradições, necessitando de auxílio para adaptar-se. Torna-se fundamental, permitir que estas sejam famílias no hospital, possibilitando o exercício de seus direitos e cidadania.

\section{REFERÊNCIAS}

1. Baggio MA, Pomatti DM, Bettinelli LA, Erdmann AL. Privacy in critical care units: the patient's rights and implications for nursing professionals. Rev Bras Enferm. 2011;64(1):25-30.

2. Aquino FM, Lemos MCM, Silva TR, Christoffel MM. A produção científica nacional sobre os direitos da criança hospitalizada. Rev Eletrônica Enferm. 2008;10:(3)796-804.

3. Sousa AA. O controle social e o empoderamento do SUS: o direito à saúde promovendo cidadania. Themis. 2010;8(2):119-128.

4. Schatkoski AM, Wegner W, Algeri S, Pedro EN. Safety and protection for hospitalized children: literature review. Rev
Latino-Am Enferm. 2009;17(3):410-416.

5. Alves CA, Deslandes SF, Mitre RMA. A gestão do processo de trabalho da enfermagem em uma enfermaria pediátrica de média e alta complexidade: uma discussão sobre cogestão e humanização. Interface Comun Saúde Educ. 2011;15(37):351-61.

6. Dunst CJ, Hamby DW, Brookfield J. Modeling the effects of early childhood intervention variables on parent and family well-being. Journal Applied Quantitative Methods. 2007;2(3):268-288.

7. Gomes ILV, Caetano R, Jorge MSB. Compreensão das mães sobre a produção do cuidado pela equipe de saúde de um 
hospital infantil. Rev Bras Enferm. 2010;63(1):84-90.

8. Lima AS, Silva VKBA, Collet N, Reichert APS, Oliveira BRG. Relações estabelecidas pelas enfermeiras com a família durante a hospitalização infantil. Texto \& Contexto Enferm. 2010;19(4):700-708.

9. Strauss A, Corbin J. Pesquisa qualitativa: técnicas e procedimentos para o desenvolvimento da teoria fundamentada. Porto Alegre: Artmed; 2008.

10. Glaser BG, Strauss AL. The discovery of grounded theory. New York: Aldine; 1967.

11. Ministério da Saúde. Resolução no 196, de 10 de outubro de 1996. Dispõe sobre diretrizes e normas regulamentadoras de pesquisa envolvendo seres humanos. Diário
Oficial da União de 1996;Seção 1.

12. Holanda ER, Collet N. Scholarization of hospitalized children from a family perspective. Texto \& Contexto Enferm. 2012;21(1):34-42.

13. Quirino DD, Collet N, Neves AFGB. Hospitalização infantil: concepções da enfermagem acerca da mãe acompanhante. Rev Gaúcha Enferm. 2010;31(2): 300-306.

14. Schneider CM, Medeiros LG. Criança hospitalizada e o impacto emocional gerado nos pais. Unoesc Ciênc. ACHS. 2011;2(2):140-154.

15. Côa TF, Pettengill MAM. The vulnerability experienced by the family of children hospitalized in a pediatric intensive care unit. Rev. Esc. Enferm. USP. 2011; 45(4):825-832. 